\title{
Organic bases as additives for steam-assisted gravity drainage
}

\author{
Sean D. Brame ${ }^{1} \cdot$ Litan Li $^{1} \cdot$ Biplab Mukherjee $^{2} \cdot$ Pramod D. Patil $^{2} \cdot$ Stephanie Potisek $^{2} \cdot$ Quoc P. Nguyen $^{1}$
}

Received: 30 November 2018 / Published online: 25 June 2019

(c) The Author(s) 2019

\begin{abstract}
Steam-assisted gravity drainage (SAGD) is a mature technology for bitumen recovery from oil sands. However, it is an energy-intensive process that requires large amounts of steam to heat and mobilize bitumen. The purpose of this work is to develop ways to enhance SAGD performance through the use of organic base additives. The research is approached from three focus areas that supplement and guide each other: characterization tests, sand-pack floods, and computational simulation. A number of key mechanisms for enhancing oil recovery were identified, high-temperature additive characterization tests were developed, and promising alkalis were tested in porous media. Simulation was employed to history-match sandpack flood production data, in order to demonstrate the effect of an additive on the oil-water relative permeability. Based on these results, it was concluded that oxygenated organic bases had the most potential for improving bitumen recovery through reducing the oil-water interfacial tension (IFT) by increasing the $\mathrm{pH}$ of the system. These organic bases favorably modify the interfacial energies between the immiscible oil-water phases and enable them to flow easily through the porous media during production. Sand-pack flood tests have successfully demonstrated a 10\%-15\% improvement in bitumen recovery, over baseline, in the presence of IFT-reducing additives. Simulation results further showed that an IFT reduction had a positive impact on SAGD performance. This work demonstrates the potential of organic bases to improve not only SAGD, but other steam injection processes. Furthermore, a number of experimental methods were developed, tried, and tested during the course of this work.
\end{abstract}

Keywords Heavy oil $\cdot$ Steam flood $\cdot$ Low interfacial tension $\cdot$ Wettability $\cdot$ Enhanced oil recovery $\cdot$ Organic bases

\section{List of symbols}

$k_{\mathrm{rw}} \quad$ Water relative permeability at $S_{\mathrm{w}}$

$k_{\text {row }} \quad$ Oil relative permeability at $S_{\mathrm{w}}$

$k_{\text {rwro }} \quad$ Water relative permeability at residual oil

$k_{\text {rocw }}$ Oil relative permeability at connate water

$S_{\mathrm{w}} \quad$ Water saturation

$S_{\mathrm{wc}} \quad$ Connate water saturation

$S_{\text {orw }} \quad$ Residual oil saturation in the presence of water

$Z_{\mathrm{w}} \quad$ Water Corey exponent

$Z_{\text {ow }} \quad$ Oil Corey exponent

Edited by Yan-Hua Sun

Quoc P. Nguyen

quoc_p_nguyen@mail.utexas.edu

1 Petroleum and Geosystems Engineering Department, The University of Texas at Austin, 200 E. Dean Keeton, Austin, TX 78712, USA

2 The Dow Chemical Company, 230 Abner Jackson Pkwy, ECB 2A183, Lake Jackson, TX 77566, USA

\section{Introduction}

At typical oil sands reservoir temperatures $\left(4-38^{\circ} \mathrm{C}\right)$, bitumen is highly viscous and practically immobile (Dusseault 2001). To reduce bitumen viscosity, steam is typically used due to its price, availability, and high heat capacity. In steamassisted gravity drainage (SAGD), steam is injected at high temperature and pressure underground into the oil sands reservoir through sets of horizontal wells (Butler 1994). The injected steam propagates in the formation and forms a steam chamber along the horizontal length. At the edge of the steam chamber, steam condenses, liberating its heat, and causes a reduction in the bitumen viscosity, which allows the oil to gravity-drain along with condensed water into production wells. The production wells are sets of horizontal wells located below the steam injection wells. Figure 1 shows a conceptual diagram of the process.

Due to the fact that large quantities of water and natural gas are needed for steam generation and that associated unwanted $\mathrm{CO}_{2}$ emissions are generated from SAGD operations, there is motivation to improve the efficiency 


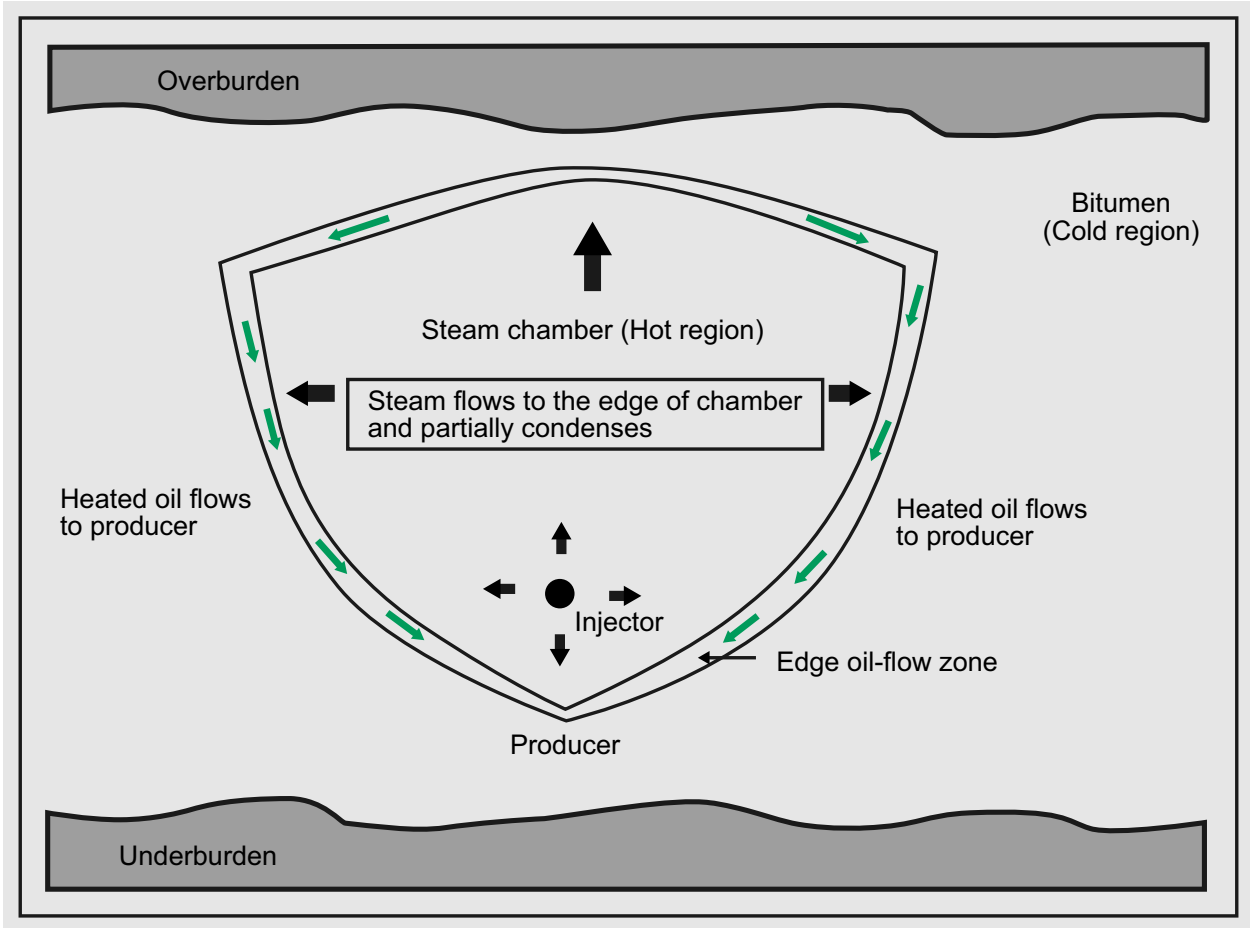

Fig. 1 Schematic of the SAGD process (reproduced from Ghasemi and Whitson 2015)

of SAGD. Since its conception, much effort had been expended to understand and model SAGD, while many innovations have been made to improve the process. Much research has been conducted on the use of solvents for heavy oils and SAGD (Haghighat and Maini 2013; Sie et al. 2018, 2019). Recently, however, studies done on non-solvent chemistries that possess potential for improving SAGD performance have become available. Oldenburg et al. (2010) studied the possibility of using monofunctional aromatic bases and acids to reduce bitumen viscosity. Babadagli et al. (2010) explored the use of biodiesel and fatty acid monoglycerides to increase bitumen recovery via in situ methods. It is hypothesized that the additives act like surfactants. Allenson et al. (2011) demonstrated that the injection of an emulsion viscosity reducer into a borehole can reduce the viscosity of water-in-oil emulsions. Lu et al. (2014) explored the use of surfactants and nitrogen gas as an insulator. Finally, Li et al. (2015) studied the use of foam, showing through numerical simulations that mobility control can provide a more uniform steam chamber growth and reduce heat loss to the overburden.

Chemical additives have great potential to enhance bitumen recovery and can be tailored to work for SAGD, improving its efficiency and performance. In this work, the use of organic bases along with steam to improve bitumen recovery was studied. It is hypothesized that alkali could improve oil recovery in conjunction with steam at the edge of the steam chamber, called the condensation zone. This is where heated bitumen and water from the condensed steam flow toward the producing wells, as seen in Fig. 1.

A number of mechanisms have been identified as having potential for improving oil recovery. These include reducing the bitumen viscosity, increasing $\mathrm{pH}$, reducing oil-water IFT, and altering wettability to a more water-wet state. Alkali additives are assessed in terms of the efficacy of these mechanisms to improve oil recovery.

Bitumen viscosity reduction is a key mechanism that allows SAGD to work. At typical oil sands reservoir temperatures, bitumen is highly viscous and practically immobile. Fortunately, the viscosity of oil decreases exponentially with an increase in temperature (Svrcek and Mehrotra 1989). Traditionally, SAGD has relied on the latent heat of steam to decrease bitumen viscosity dramatically.

Capillary forces trap oil in pores, requiring a viscous, buoyancy, or gravity force high enough to move the oil. The capillary pressure is low overall in an oil sands reservoir; however, low permeability streaks exist. Therefore, there are high capillary pressure localizations on the pore scale. In addition, the relative permeabilities of oil and water increase as the oil-water IFT decreases. Amaefule and Handy (1982) have shown using surfactant solutions that the oil-water relative permeabilities increase with decreasing oil-water IFT at the same water saturations. In SAGD, there is very little viscous force driving bitumen to the production well. The process relies on gravity to drain bitumen along the edge of the steam 
chamber, where the bitumen drains along with condensed steam in the condensation zone. A reduction in oil-water IFT could decrease the capillary pressure and increase the relative permeability enough such that the bitumen drains across pore throats under the influence of gravity. Alkalis are agents that can be used to decrease the oil-water IFT by chemical reactions with the organic acids in the oil to produce an in situ surfactant called natural soap (Hirasaki et al. 2011; Sheng 2015).

Lowering the oil-water IFT also promotes the formation of emulsions. Emulsions are dispersions of a liquid within another liquid (Alvarado and Marsden 1979). For example, oilin-water emulsion is a fluid with oil dispersed in the aqueous phase. By having oil dispersed in water at low IFT, the flow of oil is promoted due to the lack of competition between the oil and water phases to flow through a pore space. As alkalis are able to lower IFT, they can also promote the formation of emulsions. Oil-in-water emulsions are targeted, as they are less viscous than water-in-oil emulsions.

The wettability of a reservoir rock is the tendency of a fluid to spread over or adhere to its surface. In the case of a rock/oil/ brine system, it is a measure of the rock preference for oil or for water (Warner 2015). Owens and Archer (1971) showed that the ultimate oil recovery and oil relative permeability increased with increasing water-wetness in some sandstone cores. Similar to reducing oil-water IFT, the use of alkalis can shift the wettability of a rock to a more water-wet case (Cooke et al. 1974).

The purpose of this work is to study the potential for using alkaline chemicals as additives to improve the performance of the SAGD process for the recovery of bitumen. The primary metrics to be quantified are the ultimate recovery and the recovery rate of bitumen (or steam-to-oil ratio). To achieve this goal, a number of tasks were executed from three different focus areas: screening/characterization tests, sand-pack floods, and simulation. A number of high-temperature additive characterization tests were developed to demonstrate each additive's potential to improve recovery through the discussed mechanisms. Promising additives from the characterization tests were tested in porous media through the use of sandpack floods with water at high temperatures, mimicking SAGD conditions at the condensation zone. Core-scale simulations were developed of the sand-pack in CMGTM STARS to construct the system's relative permeability curves through history matching. Comparisons between the base case and additiveenhanced cases were made to reveal how the relative permeability changes in the presence of an additive. The three focus areas supplement each other in building strong conclusions on the efficacy of promising additives for improving the SAGD process.

\section{Materials and experimental methods}

\subsection{Materials}

Throughout the course of the study, six additives were tested (Table 1). Due to the proprietary nature of the chemistry, the details cannot be disclosed. Additive characterization tests were performed on these bases, and select additives were chosen for sand-pack flooding experiments.

The aqueous solutions were prepared with deionized water at $0.5 \mathrm{wt} \%$ additive concentration and $1.0 \mathrm{wt} \% \mathrm{KCl}$. Note that even though this brine salinity is not uncommon in oil reservoirs (Blondes et al. 2017), it was intended to match specific field conditions.

The bitumen used in the sand-pack flood experiments was sourced from a heavy oil formation in Alberta, Canada, which is where SAGD is traditionally utilized. At room temperature, the bitumen viscosity is around $123,000 \mathrm{cP}$. An experimental temperature of $150{ }^{\circ} \mathrm{C}$ was chosen to mimic the condensation zone. At the experimental temperature, the viscosity is around $19.40 \mathrm{cP}$. The density of the bitumen is about $1.00 \mathrm{~g} / \mathrm{mL}$ at room temperature and $0.90 \mathrm{~g} / \mathrm{mL}$ at experimental conditions. Density measurements were made using a high-pressure densitometer at controlled temperatures in an air oven (Saryazdi et al. 2013).

\subsection{Methods}

\subsection{1 $\mathrm{pH}$ measurement}

Measuring the $\mathrm{pH}$ of aqueous solutions containing base allows evaluating the capacity of additives to form natural surfactants. As previously explained, the primary mechanism by which alkali additives work is to form natural surfactants through increasing the aqueous solution $\mathrm{pH}$ (Castor et al. 1981). The measurements included using a Hanna Instruments Edge $\mathrm{pH}$ meter. The additives were heated to $150{ }^{\circ} \mathrm{C}$ and aged for 5 weeks. After aging, the additive was allowed to cool to room temperature. The $\mathrm{pH}$ electrode was submerged into the aged additive solution. The $\mathrm{pH}$ value stabilized in less than a minute was recorded.

Table 1 List of chemical additives and associated chemical family

\begin{tabular}{ll}
\hline Name & Chemical family and characteristic \\
\hline Organic Base 1 & Short-chain organic base \\
Organic Base 2 & Long-chain organic base \\
Organic Base 3 & Specialty organic base \\
Organic Base 4 & Short-chain oxygenated organic base \\
Organic Base 5 & Long-chain oxygenated organic base \\
Organic Base 6 & Specialty oxygenated organic base \\
\hline
\end{tabular}




\subsubsection{Emulsion phase behavior}

The purpose of the phase behavior test was to study whether brine and bitumen can form emulsions in the presence of a base by lowering the oil-water IFT. Additives that cause emulsions to form in an aqueous solution were considered attractive candidates for testing in permeable media. However, the creation of stable micro-emulsions is unwanted. The purpose of the additive solution is to act as a dispersant to create relatively unstable bitumen-in-water emulsions that allow for easy separation of the two phases. Therefore, additives were not only screened for the formation of emulsions, but also for their degree of gravity-driven phase separation. Furthermore, the solutions were screened for the formation of a gel phase, which is viscous. Gel formation is counterproductive to the aim of using additives to help ease the flow of bitumen.

Additive solutions were sealed in 5-mL glass pipettes. The additive solution was transferred into the pipettes, and then bitumen was added to make a total water-to-oil ratio of 1.5. This ratio was kept constant across all phase behavior experiments. The pipettes were sealed and placed inside a convection oven at $150{ }^{\circ} \mathrm{C}$ for 7 days. Three pipettes with varying salinities were prepared in this manner for each of the six organic bases. Potassium chloride was used to vary the salinity, and solutions of $0.0,1.0$, and $2.0 \mathrm{wt} \% \mathrm{KCl}$ were prepared for each additive. Since the aqueous additive solution and bitumen interface was small, the pipettes were removed from the oven once per day, slowly tilted to promote additive-bitumen contact, and observations on the transient solubilizations of the aqueous and oleic phases were made. At the end of 7 days, the pipettes were removed from the oven, and pictures were taken before and immediately after tilting.

\subsubsection{Wettability}

Wettability alteration experiments were done using hightemperature characterization tests in a three-phase system of additive solution, bitumen, and a mineral surface. The objective of these experiments was to test whether the chemical can alter the wettability of the mineral surface or move the contact line between the three phases (the line where the aqueous, bitumen, and solid phases meet) and thus clean bitumen off the surface. To create a clear contact line, slender quartz crystals, calcite crystals, and small Berea sandstone plugs were halfway dipped and aged in bitumen. Quartz crystals were used as they represent a clean silica surface that lacks mineral contamination. On the other hand, Berea plugs were used as they represent a complex sand system. These media provide two extremities for silica sand conditions. However, these minerals have low surface energies, and at high temperatures, bitumen may not adhere well to the surface. For this reason, calcite crystals were utilized as well due to their high surface energy (Arsalan et al. 2013a, b).

The following is a prototypical procedure using slender quartz or calcite crystals. The bottom half of each crystal was submerged in dewatered bitumen inside glass vials. The vials were capped, placed in a convection oven at $80^{\circ} \mathrm{C}$, and aged. The crystals were carefully pulled out of the bitumen vials. The crystals were then placed into high-pressure cells. The aqueous additive solution was then added into the cell. Nitrogen was bubbled through the solution to deoxygenate it and displace the air at the top. The cells were then sealed and placed inside a convection oven at 150 or $250^{\circ} \mathrm{C}$. After 3 days, the cells were removed from the oven. The crystals were removed and observed.

The experimental procedure used with 1-inch-diameter Berea core plugs was the same except for a couple improvements and modifications. These plugs were dipped halfway into bitumen and aged. It was found that aging for 4 days at room temperature before raising the temperature to $80^{\circ} \mathrm{C}$ created a clear contact line halfway up the plug. Once the cells were prepared, the plugs were placed into the cell filled with the additive solution, with the unaged side on the bottom. These cells were heated at $150{ }^{\circ} \mathrm{C}$.

\subsubsection{Enhanced oil recovery in porous media}

Alkali solutions that were deemed to have high potential in improving bitumen recovery from the characterization experiments were tested in sand-pack floods. Injection solutions were fed at $150{ }^{\circ} \mathrm{C}$, and back pressure regulators were used to keep the injection solutions in the liquid state. The primary metrics to be quantified were the ultimate recovery and the recovery rate of bitumen.

Figure 2 shows the schematic of the sand-pack flood setup used. The 29.1-cm-long, 3.10-cm-diameter sand-pack core holder was placed in a convection oven heated to $150{ }^{\circ} \mathrm{C}$. Absolute pressure transducers were connected to the inlet and outlet with three differential pressure transducers measuring pressure within three sections of the sand-pack. The back pressure was set at 500 psig to ensure that water remained in the liquid state. The injection system included two pumps to inject a brine solution and the additive solution separately. The injection stream included a 6 -ft coil that was placed in the oven to ensure that the injected fluid would be preheated to the target temperature before entering the sand-pack. The outlet lines and back pressure regulators were placed in a water bath at $80^{\circ} \mathrm{C}$ to help ease the flow of viscous bitumen. A fraction collector was used to collect the produced effluent, which was used to determine the amount of bitumen recovered.

Solutions were injected in the liquid state at $150{ }^{\circ} \mathrm{C}$ with the use of back pressure regulators, and 140-270 mesh sand 


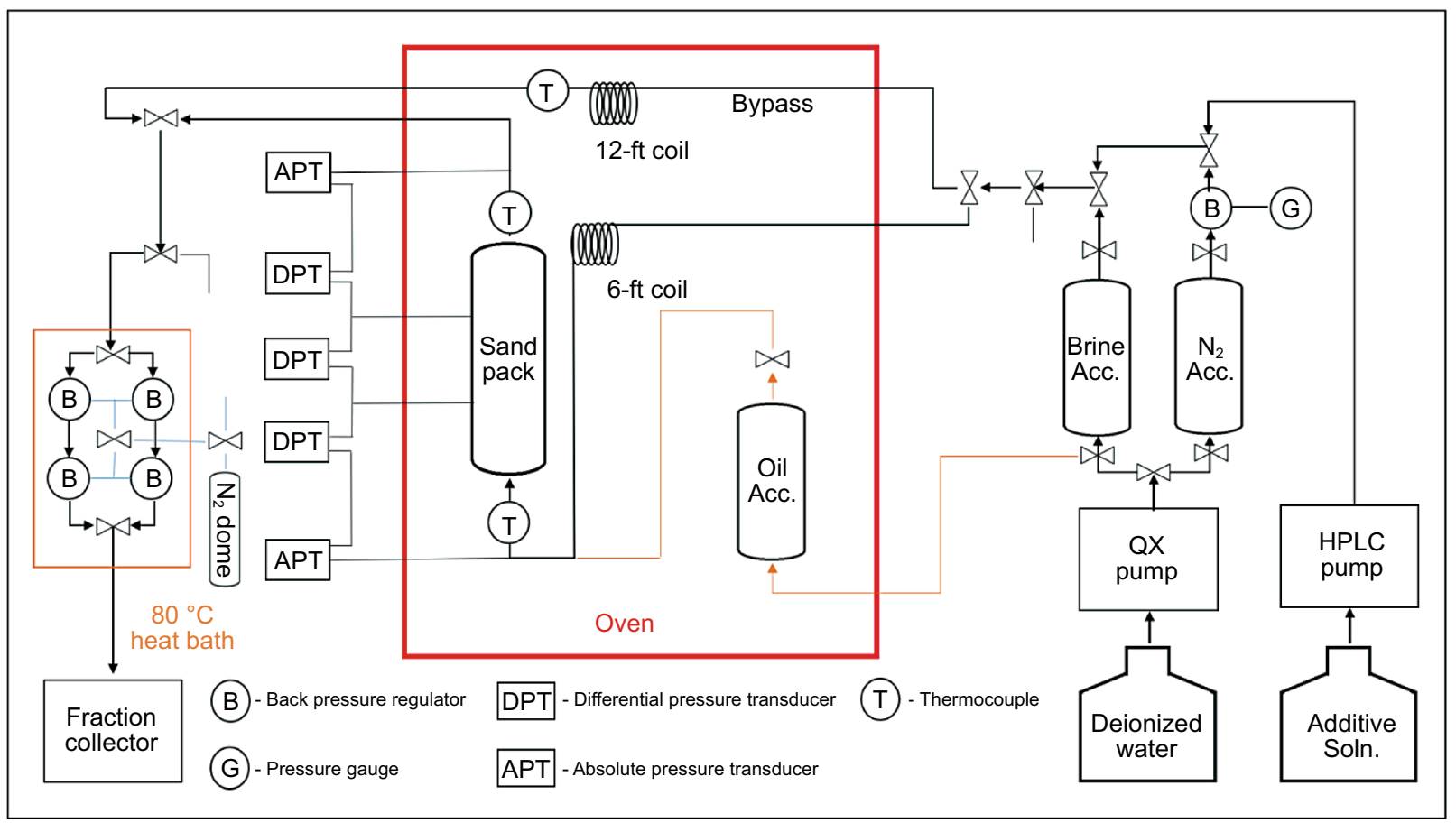

Fig. 2 Sand-pack setup

was used as the porous medium in these experiments. Loose, unconsolidated sand was used as this was more representative of an SAGD reservoir formation, compared to rock cores. The sand-pack porosity and absolute permeability were measured. The porosity of the sand-packs ranged from $36 \%$ to $39 \%$, while the permeability ranged from 1.9 to 3.1 Darcy. The sand-pack was then saturated with bitumen, and the oil saturation was recorded. After heating to $150{ }^{\circ} \mathrm{C}$, the aqueous solution was injected in a gravity-stable displacement regime. A top-down strategy was also employed in a few core floods to demonstrate that a gravity-stable injection would yield more representative results. Injection fluid was either $1 \mathrm{wt} \% \mathrm{KCl}$ brine, for a base case, or the additive solution. Comparison of the two cases allowed us to probe whether the additive had an effect in improving recovery. Injection continued until the produced effluent reached $100 \%$ water cut.

\subsubsection{Simulation and history matching}

One method to visualize a change in oil-water IFT and wettability is through relative permeability curves. Relative permeability curves from each of the sand-pack floods were obtained to confirm that the presence of an additive reduces IFT and alters wettability, which improves the recovery of oil by increasing the oil relative permeability. Numerical simulation studies were used to extract the relevant relative permeability curves from each sand-pack flood. Simulation models were developed using CMG ${ }^{\mathrm{TM}}$ STARS that corresponded with the sand-pack floods. History-matching techniques were then employed to develop the corresponding relative permeability curves, as all other properties were known.

The base relative permeability curves for each model were constructed using the in-program generator using the Generalized Corey Equations, based on data from the SAGD Underground Testing Facility (UTF) in Alberta, Canada (Siu et al. 1991; Walls et al. 2003). Relative permeability parameters were later varied during the history-matching study to develop the correct relative permeability curves for each sand-pack flood. The oil-water permeability curves are correlated by the following relationships, the Generalized Corey Equations (Brooks and Corey 1964):

$k_{\mathrm{rw}}=k_{\mathrm{rwro}}\left(\frac{S_{\mathrm{w}}-S_{\mathrm{wc}}}{1-S_{\mathrm{orw}}-S_{\mathrm{wc}}}\right)^{Z_{\mathrm{w}}}$.

$k_{\text {row }}=k_{\text {rocw }}\left(\frac{1-S_{\mathrm{w}}-S_{\text {orw }}}{1-S_{\text {orw }}-S_{\mathrm{wc}}}\right)^{Z_{\text {ow }}}$.

where Eq. 1 represents the water relative permeability curve and Eq. 2 represents the oil relative permeability curve. Both equations are a function of water saturation $\left(S_{\mathrm{w}}\right)$. A shift in the relative permeability end points $\left(k_{\mathrm{rwro}}, k_{\mathrm{rocw}}, S_{\mathrm{wc}}, S_{\text {orw }}\right)$ demonstrates a change in wettability, while a decrease in 
the Corey exponents $\left(Z_{\mathrm{w}}, Z_{\mathrm{ow}}\right)$ demonstrates a reduction in IFT, resulting in less curvature in the relative permeability curves.

\section{Results and discussion}

\subsection{Effect of alkali on the $\mathrm{pH}$ of the aqueous phase}

Every organic base was able to increase $\mathrm{pH}$ to around 10-12 at only $0.2 \mathrm{wt} \%$ concentration after 5 weeks of aging at $150{ }^{\circ} \mathrm{C}$. Therefore, it can be inferred that the bases should be quite effective at forming in situ surfactants at high temperatures, which can then lower IFT.

\subsection{Effect of alkali on oil-water emulsion tendency}

Table 2 shows the results of the emulsion tendency tests. Additive solutions were observed before and after tilting of the pipettes. In Table 2, $E$ signifies that emulsions formed and were visible, while $N E$ signifies no appreciable forming of emulsions.

No emulsions formed in the base case where no additive was added. All visible emulsions were oil-in-water emulsions and none formed a gel phase. This is significant as it proves the efficacy of the organic bases in forming emulsions to aid bitumen flow. The lack of gel formation also demonstrates that the organic bases succeed in their purpose of easing flow. The majority of organic base solutions had visible emulsions before tilting, except for Organic Base 2 at $2.0 \mathrm{wt} \% \mathrm{KCl}$ and Organic Base 3 at all salinities. Higher salinity concentrations disrupt the ability for emulsions to form (Wang and Alvarado 2008). However, after tilting, all organic base solutions had visible emulsions. Figure 3 compares the base case and the Organic Base 4 solution case. It was observed that emulsions remained stable for longer in solutions containing Organic Bases 4 through 6. The solution was also darker for these additives. This indicates improved oil-in-water emulsion formation as evidenced by smaller oil droplets in the aqueous phase. In all pipettes, the two phases were able to separate over time due to the density differences. Therefore, no micro-emulsions formed.

Overall, all the organic bases successfully performed as dispersants. However, Organic Bases 4-6, the oxygenated organic bases, show the most promise for improving oil recovery in permeable media as evidenced by more robust oil-in-water emulsion formation, compared to the other organic bases.

\subsection{Effect of alkali on mineral surface wettability}

The results of the wettability tests using quartz crystals were inconclusive. Bitumen was completely peeled off the surface of the crystals that were aged in a $1 \mathrm{wt} \% \mathrm{KCl}$ solution acting as the base case. No additives were present in the solution. This was due to the smooth topology of the quartz crystals, as well as their low surface energy (Arsalan et al. 2013a, b).

Fig. 3 Phase behavior for no additive case (a) and Organic Base 4 (b)

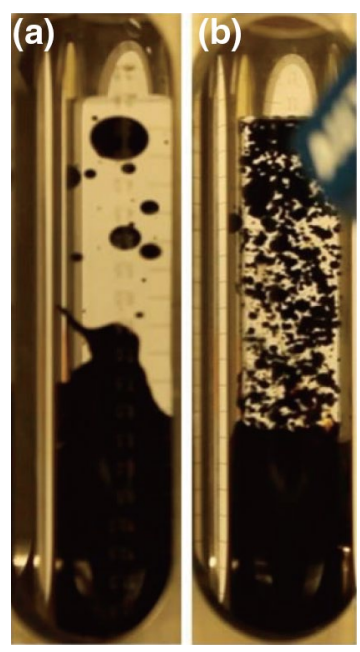

Table 2 Chemical additive phase behavior at $0.5 \mathrm{wt} \%$ concentration and $150{ }^{\circ} \mathrm{C}$

\begin{tabular}{|c|c|c|c|c|c|c|}
\hline \multirow[t]{3}{*}{ Additive } & \multicolumn{6}{|c|}{ Salinity, wt $\% \mathrm{KCl}$} \\
\hline & \multicolumn{2}{|l|}{0.0} & \multicolumn{2}{|l|}{1.0} & \multicolumn{2}{|l|}{2.0} \\
\hline & Before tilting & After tilting & Before tilting & After tilting & Before tilting & After tilting \\
\hline No additive (base case) & NE & NE & NE & NE & NE & NE \\
\hline Organic Base 1 & $\mathrm{E}$ & $\mathrm{E}$ & $\mathrm{E}$ & $\mathrm{E}$ & $\mathrm{E}$ & $\mathrm{E}$ \\
\hline Organic Base 2 & $\mathrm{E}$ & $\mathrm{E}$ & $\mathrm{E}$ & $\mathrm{E}$ & $\mathrm{NE}$ & $\mathrm{E}$ \\
\hline Organic Base 3 & $\mathrm{NE}$ & $\mathrm{E}$ & NE & $\mathrm{E}$ & $\mathrm{NE}$ & $\mathrm{E}$ \\
\hline Organic Base 4 & $\mathrm{E}$ & $\mathrm{E}$ & $\mathrm{E}$ & $\mathrm{E}$ & $\mathrm{E}$ & $\mathrm{E}$ \\
\hline Organic Base 5 & $\mathrm{E}$ & $\mathrm{E}$ & $\mathrm{E}$ & $\mathrm{E}$ & $\mathrm{E}$ & $\mathrm{E}$ \\
\hline Organic Base 6 & $\mathrm{E}$ & E & $\mathrm{E}$ & $\mathrm{E}$ & $\mathrm{E}$ & $\mathrm{E}$ \\
\hline
\end{tabular}

$E$ emulsions visible; $N E$ no emulsions visible 
Fig. 4 Quartz crystals aged in bitumen heated in $1 \mathrm{wt} \% \mathrm{KCl}$ for 3 days at $250{ }^{\circ} \mathrm{C}$

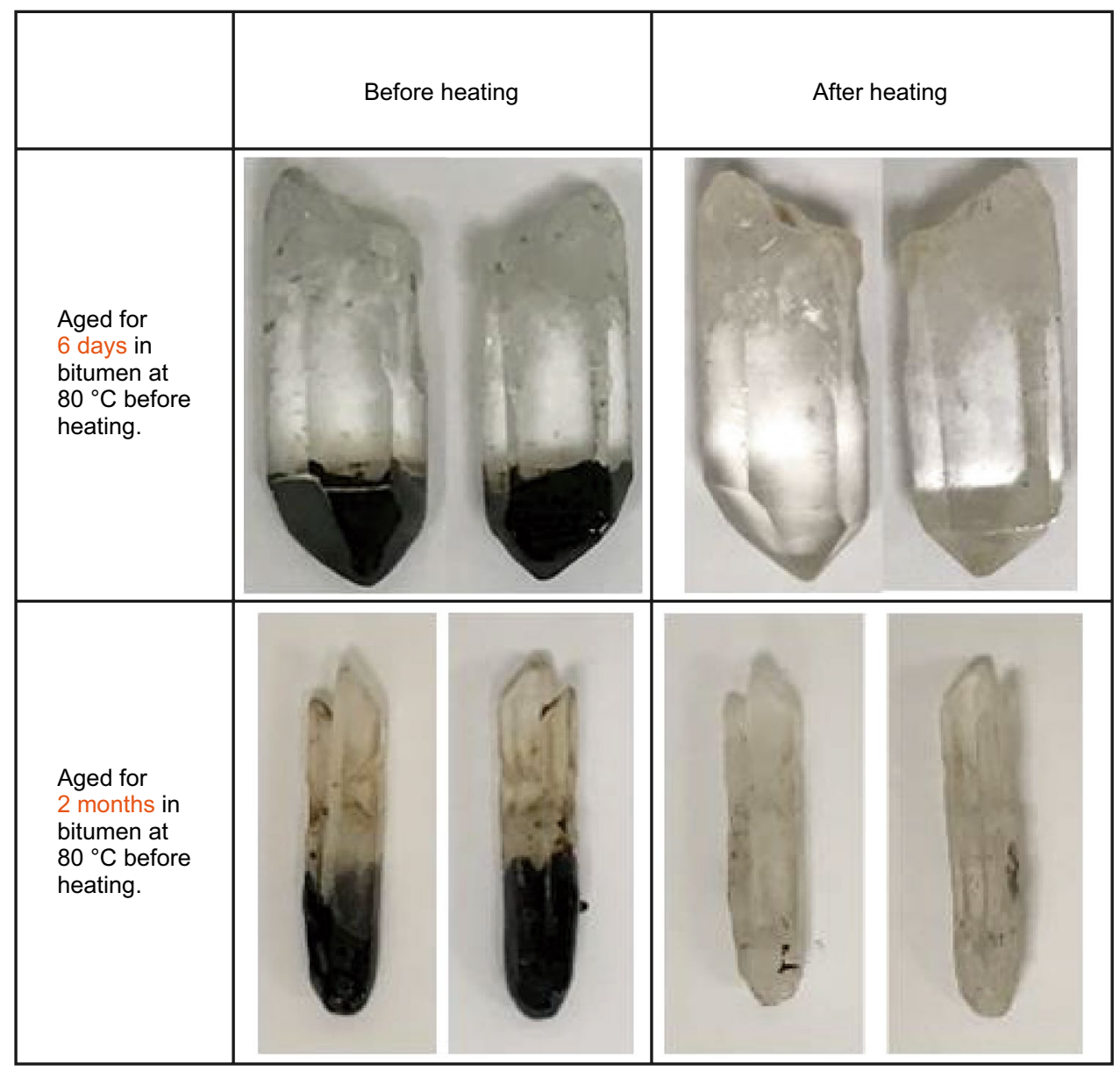

Even after aging in bitumen for 2 months, the crystals were completely cleaned after heating in the base-case solution. The degree of cleaning is seen in Fig. 4. It is safe to assume that additive solutions would also completely peel bitumen off the surface. Creating a contact line using pure quartz crystals would not work, so sandstone plugs and calcite crystals were used instead.

For experiments involving the Berea sandstone plugs, several organic bases were tested for their ability to move the contact line or to peel off significant amounts of bitumen. Organic Bases 1, 2, 4, and 5 were chosen for these experiments. In each of the additive cases, neither significant movement of the contact line nor significant peeling of bitumen was observed. In all of the cases (Fig. 5), these Berea core plugs did not show that the additives tested move the macroscopic contact line downwards appreciably, and no shown signs of significant bitumen removal from the surface of the plugs appeared.

The calcite crystals were a more effective material in testing the ability of an additive to peel bitumen from its surface. As a base case, the calcite crystals were heated in the presence of $1 \mathrm{wt} \% \mathrm{KCl}$ for 3 days at 150 and $250{ }^{\circ} \mathrm{C}$. Beading up of bitumen droplets and a partial removal of bitumen from the surface at both temperatures were observed. Unlike the quartz crystals, the bitumen was not completely peeled off from the surface of the calcite mineral, even after heating at $250{ }^{\circ} \mathrm{C}$. The calcite surfaces were much more oil-wet than those of quartz, enabling some bitumen to remain. Successful additives should remove significantly more bitumen from the surface than the base solution. However, the use of organic base shows that the degree of bitumen removal and contact line movement were not more significant than the base case. Figure 6 shows similar degrees of cleaning between the base case and Organic Bases 4 and 5. The effect of hydrophobicity of organic bases (Organic Bases 3 and 6) was tested as well. Again, bitumen removal and contact movement were not more significant compared to the base case.

Overall, the additives were not as successful at wettability alteration and contact line movement as compared to oil-water interfacial tension reduction. The use of quartz crystals was unsuccessful, as bitumen was completely cleaned off the surface, even without an additive. Experiments using sandstone plugs and calcite demonstrated that the organic bases could not alter wettability. Based on the results, it can be hypothesized that wettability might not play 
Fig. 5 Berea plugs aged in bitumen heated in various organic base solutions for 3 days at $150{ }^{\circ} \mathrm{C}$

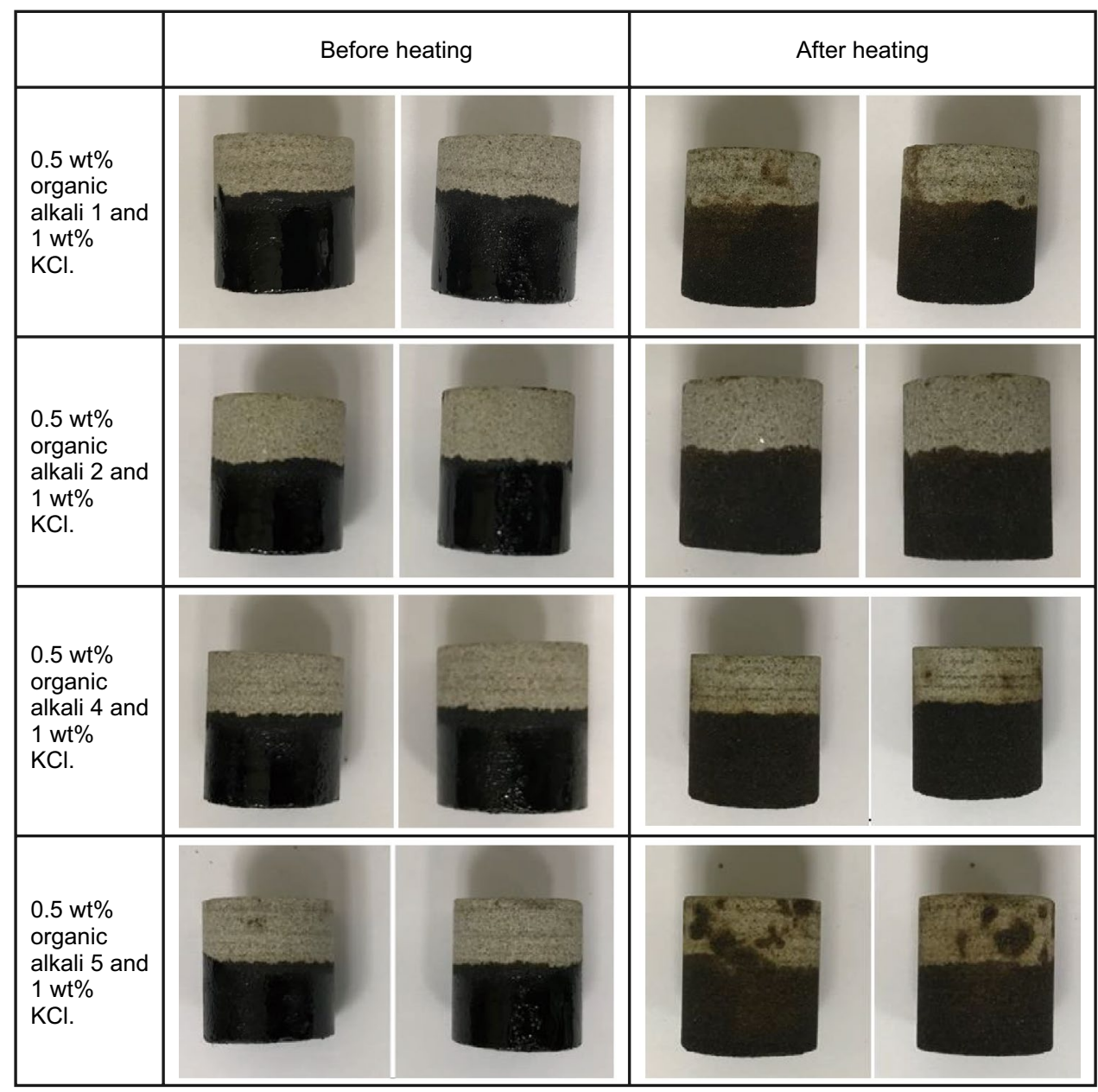

a critical role in enhancing bitumen recovery using the tested organic bases.

\subsection{Effect of alkali on oil recovery}

Four sand-pack core floods were conducted. Organic Base 4 through 6 showed the strongest formation of oil-in-water emulsions, as evidenced by darker and more stable emulsions. Organic Base 4 was chosen as the test additive, as it showed the best results in terms of natural surfactant and emulsion formation. The first two core floods used a topdown injection strategy to mimic the downward flow of hot water and bitumen in the condensation zone toward a producer in SAGD operations. However, it was hypothesized that due to density contrasts between water and bitumen, these floods would not yield accurate results due to poor displacement. These core floods were conducted to demonstrate the need for more displacement stability control in experiments to test additives. To better determine the effect of an additive, the next two core floods employed a gravitystable injection strategy, injecting from the bottom of the sand-pack to the top.
Sand-pack Flood 1 was injected with an additive solution containing $0.5 \mathrm{wt} \%$ Organic Base 4 in $1 \mathrm{wt} \% \mathrm{KCl}$ brine. Sand-pack Flood 2 was a base case, with $1 \mathrm{wt} \% \mathrm{KCl}$ brine as the injection fluid. Sand-pack Flood 3 contained a $0.5 \mathrm{wt} \%$ Organic Base 4 solution with the same brine, while Sandpack Flood 4 was a repeat base case with the new injection strategy. Table 3 provides details for all four sand-pack floods. The sand-pack permeabilities are within the typical Canadian oil sands' range of 0.5-5 D (Dusseault 2001). An injection rate of $2 \mathrm{PV} /$ day was selected.

Figure 7 shows recovery curves and oil cut for Sand-pack Floods 1 and 2, with $E_{\mathrm{R}}$ as recovery efficiency in mass fraction of original oil in place (OOIP). Figure 7 shows that the recovery was slightly better when using the organic base, with an increase in recovery starting at four pore volumes (PV). At 14 injected pore volumes, Flood 1 recovered about $3 \%$ more oil. Flood 1 produced $60.9 \%$ of the bitumen, while Flood 2 produced $58.0 \%$. Since the sand-packs are relatively homogeneous, the comparison between Sand-pack Floods 1 and 2 should not suffer from difference in pore structures. Therefore, although the recovery improvement was modest, it was concluded that Organic Base 4 was able to improve 
Fig. 6 Calcite crystals aged in bitumen heated in various organic base solutions for 3 days at $150{ }^{\circ} \mathrm{C}$
Table 3 Sand-pack flood parameters

\begin{tabular}{|l|c|c|}
\hline & Before heating & After heating \\
\hline $\begin{array}{l}\text { Heated at } \\
150^{\circ} \mathrm{C} \text { in } \\
1 \mathrm{wt} \% \mathrm{KCl} \\
\text { for } 3 \text { days }\end{array}$ & & \\
\end{tabular}

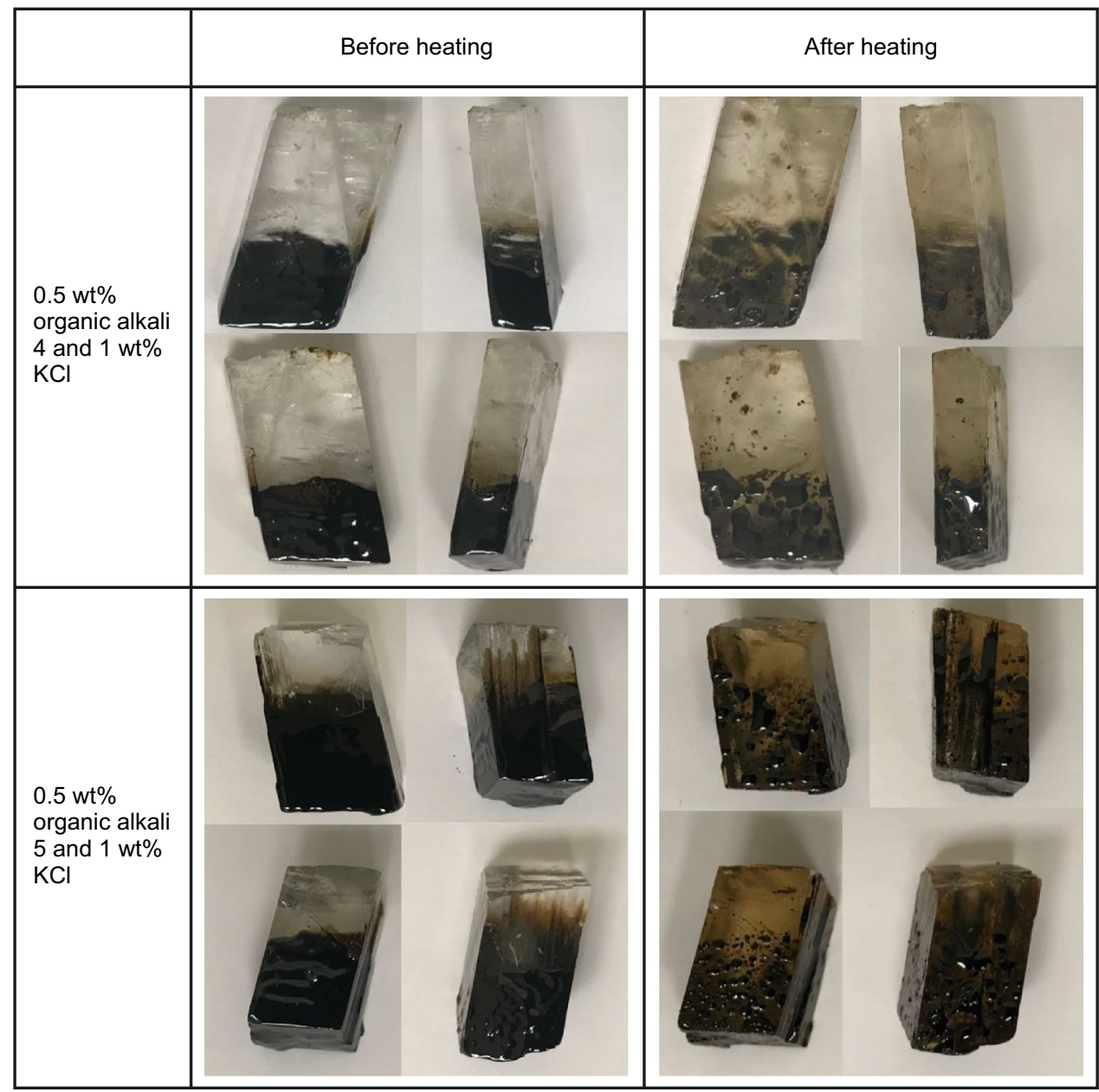

\begin{tabular}{|c|c|c|c|c|c|c|}
\hline Flood & Porosity & $\begin{array}{l}\text { Absolute per- } \\
\text { meability, D }\end{array}$ & $\begin{array}{l}\text { Original oil in } \\
\text { place (OOIP), g }\end{array}$ & Injection fluid & Injection direction & $\begin{array}{l}\text { Injection } \\
\text { rate, } \mathrm{mL} / \\
\text { min }\end{array}$ \\
\hline Flood 1 & 0.36 & 2.6 & 73 & $\begin{array}{l}0.5 \mathrm{wt} \% \\
\text { Organic } \\
\text { Base } 4 \text { and } 1 \\
\text { wt } \% \mathrm{KCl}\end{array}$ & Top to bottom & 0.1108 \\
\hline Flood 2 & 0.38 & 2.3 & 75 & $1 \mathrm{wt} \% \mathrm{KCl}$ & Top to bottom & 0.1147 \\
\hline Flood 3 & 0.39 & 3.1 & 72 & $\begin{array}{l}0.5 \mathrm{wt} \% \\
\text { Organic } \\
\text { Base } 4 \text { and } 1 \\
\text { wt } \% \mathrm{KCl}\end{array}$ & Bottom to top & 0.1203 \\
\hline Flood 4 & 0.39 & 1.9 & 72 & $1 \mathrm{wt} \% \mathrm{KCl}$ & Bottom to top & 0.1177 \\
\hline
\end{tabular}




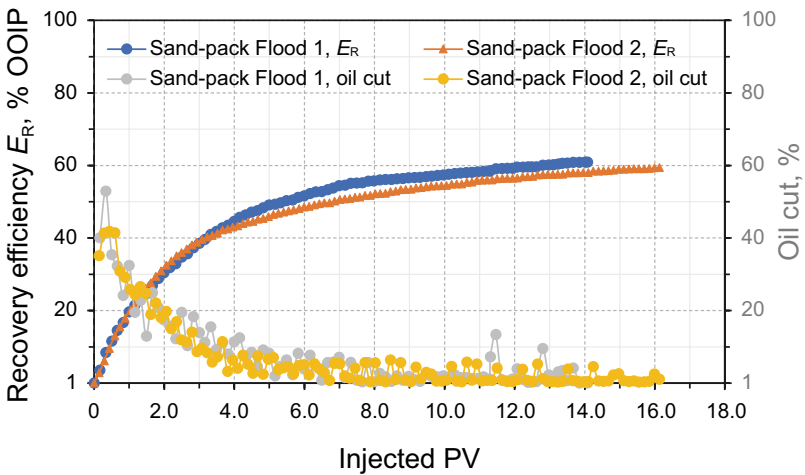

Fig. 7 Effect of Organic Base 4 on recovery efficiency. Fluids were injected from the top and produced from the bottom

bitumen recovery and oil rate. However, as seen in the figure, the oil cut was relatively low throughout the experiments. As expected, early water breakthrough was observed for both floods. This was due to the density and viscosity contrast of bitumen and water, as well as the lowered IFT. Despite being low, the density contrast caused bitumen to preferentially flow upward and water downward. The contrast in viscosity allowed the aqueous solution to easily finger through toward the outlet. At $150{ }^{\circ} \mathrm{C}$, the viscosity of the bitumen is 19.40 $\mathrm{cP}$, while water's is $0.18 \mathrm{cP}$. This was further promoted by the low IFT, as the aqueous phase was able to disperse the bitumen. For this reason, this pair of sand-pack floods did not sweep the core efficiently. These resulted in a limited effect of the injected additive.

Another set of sand-pack flood experiments were conducted using a gravity-stable injection regime. This was done by switching the injection and producing line, so that fluid would be injected from the bottom and produced from the top. This was to minimize viscous fingering and to mimic a gravity-stable process, which would displace bitumen more effectively. The results of the second pair of sand-pack floods were more successful than the previous pair in demonstrating the effect of oxygenated organic bases on bitumen recovery.

Organic Base 4 was used in Flood 3, while Flood 4 was a re-run of the brine-only injection of Flood 2. Additive solution concentrations and injection rate were kept the same. The properties of the two floods were similar, except for permeability. The permeability in Flood 4 was much lower than in Flood 3, so a lower recovery is expected. To better determine the effect of Organic Base 4, changes in the relative permeability curves are analyzed after history matching.

Figure 8 shows recovery curves for Sand-pack Floods 3 and 4. Figure 8 confirms that the recovery is greater when using the additive. At 14 pore volumes, the recovery

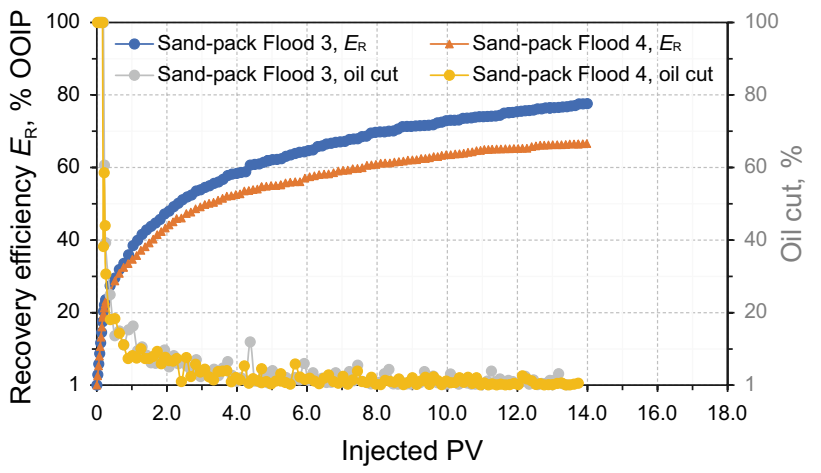

Fig. 8 Effect of Organic Base 4 on recovery efficiency. Fluids were injected from the bottom and produced from the top

is $11 \%$ greater in the additive-enhanced Flood 3 than in Flood 4. Flood 3 had a recovery of $77.6 \%$, while Flood 4 had a recovery of $66.6 \%$. The improved recovery started to occur at one pore volume. Therefore, it can be concluded that the recovery was significantly improved by the presence of Organic Base 4, despite the difference in permeability. By comparing the recoveries of all four floods, it can be determined that the bottom-to-top injection strategy greatly improved the performance of the sand-pack flood tests. Furthermore, this improvement can be observed in the oil cut, which shows initial values of $100 \%$. The contrast between the results of the experiments is due to the lack of viscous forces and density contrast playing a role, which allows better interaction between the chosen additive and the bitumen.

\subsection{Simulation and history matching}

Through the use of the history-matching technique, the matched parameters were used to plot the relative permeability curves for each sand-pack flood. The organic base-enhanced flood is compared to the base-case flood to determine the effect of alkali on increasing oil relative permeability due primarily to oil-water IFT reduction. A decrease in the curvature of the relative permeability curves would demonstrate a reduction in IFT.

Figure 9 shows the relative permeability curves for Sand-pack Floods 3 and 4. The organic base-enhanced case is shown in the dashed line. As can be seen in Fig. 9, there was a decrease in the curvature, which suggests that the oxygenated organic base was successful in increasing oil relative permeability and decreasing water relative permeability. Table 4 lists the matched parameters for this study. As seen from the parameters, the Corey exponents, $Z_{\mathrm{w}}$ and $Z_{\mathrm{ow}}$, decrease from Flood 4 to Flood 3, 


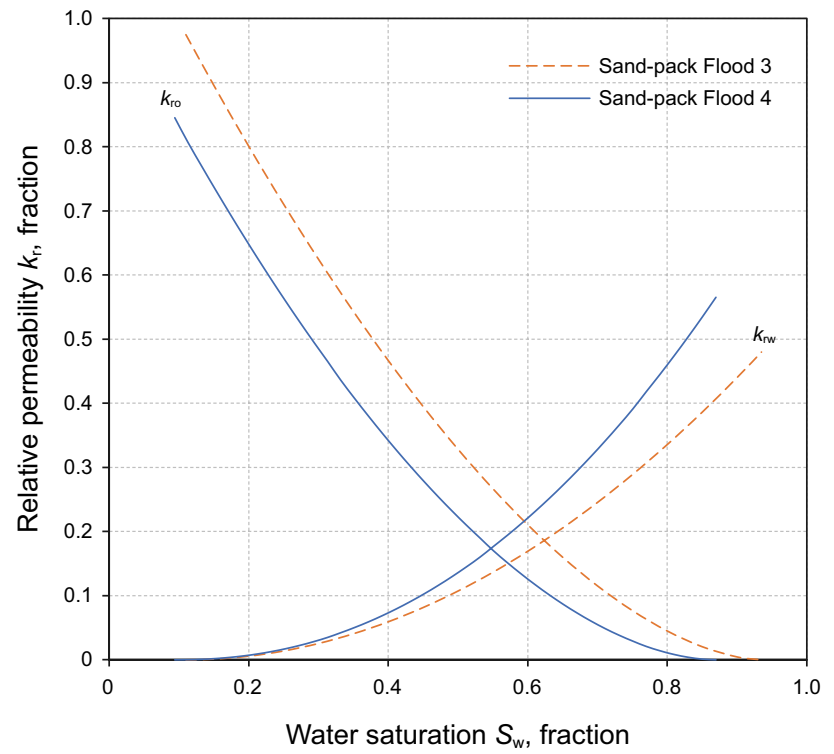

Fig. 9 Oil-water relative permeability curves of Sand-pack Floods 3 and 4

which signifies a decrease in IFT. It can be concluded that the additive has a positive effect on relative permeability alteration and, thus, oil recovery.

\section{Conclusions}

The purpose of this work was to study the potential of using organic bases to improve the performance of SAGD. A suite of high-temperature additive characterization tests was developed and executed. Several promising additives were selected to test in sand-pack floods to determine recovery potential in porous media on the laboratory scale. The following conclusions were drawn:

1. Organic bases have potential to improve bitumen recovery in SAGD. The use of organic bases to increase solution $\mathrm{pH}$ at low concentrations in order to generate natural surfactant at high temperatures was demonstrated.

2. For the additives tested, the oxygenated organic bases demonstrated the most potential for an enhanced recovery of bitumen. The oxygenated organic bases were successful in forming robust oil-in-water emulsions with no gel phase. The results indicate the additive efficacy in reducing the oil-water interfacial tension.

3. Sand-pack flood experiments demonstrated the effect of oxygenated organic bases on improving bitumen recovery at $150{ }^{\circ} \mathrm{C}$. There was around an $11 \%$ increase in recovery after 14 injected pore volumes when an additive was used in the injected fluid.

4. The relative permeability curves extracted from the experiments verified that the organic base was able to alter interfacial tension to favor oil recovery.

5. The study demonstrated the effectiveness of the designed experiments to screen additives and understand mechanisms. While tests for emulsion tendency were consolidated and successful, wettability alteration tests revealed the limitations of using quartz at elevated temperatures, as well as the limitations of bases to alter the wettability of higher surface energy minerals such as those in the Berea sandstone and calcite.

Table 4 History-matched Corey parameters for Sand-pack Floods 3 and 4

\begin{tabular}{lllllll}
\hline Flood & $\begin{array}{l}k_{\mathrm{rw}} \text { at residual } \\
\text { oil } k_{\mathrm{rwro}}\end{array}$ & $\begin{array}{l}k_{\mathrm{ro}} \text { at connate } \\
\text { water } k_{\mathrm{rocw}}\end{array}$ & $\begin{array}{l}\text { Connate water saturation } \\
S_{\mathrm{wc}} * \text { (laboratory value) }\end{array}$ & $\begin{array}{l}\text { Residual oil satu- } \\
\text { ration, } S_{\text {orw }}\end{array}$ & $\begin{array}{l}\text { Water Corey } \\
\text { exponent } Z_{\mathrm{w}}\end{array}$ & $\begin{array}{l}\text { Oil Corey expo- Error, } \% \\
\text { nent } Z_{\text {ow }}\end{array}$ \\
\hline Flood 3 & 0.480 & 0.975 & 0.110 & 0.065 & 2.0 & 1.7 \\
Flood 4 & 0.565 & 0.845 & 0.094 & 0.130 & 2.2 & 1.8 \\
\hline
\end{tabular}


6. Sand-pack flood experiments confirmed that controlled and systematic studies are needed for additive testing purposes. Despite the top-down flow of SAGD in the field, conducting experiments with a gravity-stable injection strategy is more successful due to the effect of density and gravity.

Future work would be to study the efficacy of organic bases in actual steam floods, rather than in hot water. This would include studying the transport of additives in steam and vapor at temperatures higher than $150{ }^{\circ} \mathrm{C}$. The results of this work open new possibilities for utilizing organic bases for not only SAGD operations, but all steam flooding techniques.

Acknowledgements We gratefully acknowledge the support of this research from The Dow Chemical Company.

Open Access This article is distributed under the terms of the Creative Commons Attribution 4.0 International License (http://creativeco mmons.org/licenses/by/4.0/), which permits unrestricted use, distribution, and reproduction in any medium, provided you give appropriate credit to the original author(s) and the source, provide a link to the Creative Commons license, and indicate if changes were made.

\section{References}

Allenson SJ, Yen AT, Lang, F. Application of emulsion viscosity reducers to lower produced fluid viscosity. In: Offshore technology conference, October 4-6, Rio de Janeiro, Brazil; 2011. https ://doi.org/10.4043/22443-MS.

Alvarado DA, Marsden SS. Flow of oil-in-water emulsions through tubes and porous media. SPE J. 1979;19(6):369-77. https://doi. org/10.2118/5859-PA.

Amaefule JO, Handy LL. The effect of interfacial tensions on relative oil/water permeabilities of consolidated porous media. Soc Pet Eng J. 1982;22(3):371-81. https://doi.org/10.2118/9783-PA.

Arsalan N, Palayangoda SS, Burnett D, Buiting JJ, Nguyen QP. Surface energy characterization of sandstone rocks. J Phys Chem Solids. 2013a;74(8):1069-77. https://doi.org/10.1016/j.jpcs.2013.02.027.

Arsalan N, Palayangoda SS, Burnett D, Buiting JJ, Nguyen QP. Surface energy characterization of carbonate rocks. Colloid Surf A. 2013b;436:139-47. https://doi.org/10.1016/j.colsu rfa.2013.06.004

Babadagli T, Er V, Naderi K, Burkus Z, Ozum B. Use of biodiesel as an additive in thermal recovery of heavy oil and bitumen. Soc Pet Eng J. 2010;49(11):43-8. https://doi.org/10.2118/141302-PA.

Blondes MS, Gans KD, Engle MA, Kharaka YK, Reidy ME, Saraswathula V, et al. U.S. Geological Survey National Produced Waters Geochemical Database. 2017;v2.3.

Brooks RH, Corey AT. Hydraulic properties of porous media. Hydrology papers, Colorado State University, Fort Collins, Colorado. 1964;3.

Butler RM. Steam-assisted gravity drainage: concept, development, performance and future. J Can Pet Technol. 1994;33(2):44-50. https://doi.org/10.2118/94-02-05.

Castor TP, Somerton WH, Kelly JF. Recovery mechanisms of alkaline flooding. Surf Phenom Enhanc Oil Recovery. 1981. https://doi. org/10.1007/978-1-4757-0337-5_14.
Cooke CE, Williams RE, Kolodzie PA. Oil recovery by alkaline waterflooding. J Pet Technol. 1974;26(12):1365-74. https://doi. org/10.2118/4739-PA.

Dusseault MB. Comparing Venezuelan and Canadian heavy oil and tar sands. In: Canadian international petroleum conference, 12-14 June, Calgary, Alberta; 2001. https://doi.org/10.2118/2001-061.

Ghasemi M, Whitson CH. Compositional variation in SAGD. In: SPE annual technical conference and exhibition, 28-30 September, Houston, Texas, USA; 2015. https://doi.org/10.2118/175022-MS.

Haghighat P, Maini BB. Effect of temperature on VAPEX performance. J Can Pet Technol. 2013. https://doi.org/10.2118/157799-PA.

Hirasaki G, Miller CA, Puerto M. Recent advances in surfactant EOR. SPE J. 2011;16(04):889-907. https://doi.org/10.2118/115386-PA.

Li R, Etminan SR, Chen Z. Chemical additives and foam to enhance SAGD performance. In: SPE Canada heavy oil technical conference, 9-11 June, Calgary, Alberta, Canada; 2015. https://doi. org/10.2118/174489-MS

Lu C, Liu H, Liu Q, Lu K, Wang L. Research on the effect of noncondensable gas and viscosity reducer for better SAGD performance. In: SPE heavy oil conference-Canada, 10-12 June, Calgary, Alberta, Canada; 2014. https://doi.org/10.2118/170026-MS.

Oldenburg TBP, Yarranton HW, Larter S. The effect of low molecular weight multifunctional additives on heavy oil viscosity. In: Canadian unconventional resources and international petroleum conference, 19-21 October, Calgary, Alberta, Canada; 2010. https ://doi.org/10.2118/137505-MS.

Owens WW, Archer DL. The effect of rock wettability on oil-water relative permeability relationships. J Pet Technol. 1971;23(07):8738. https://doi.org/10.2118/3034-PA.

Saryazdi F, Motahhari H, Schoeggl FF, Taylor SD, Yarranton HW. Density of hydrocarbon mixtures and bitumen diluted with solvents and dissolved gases. Energy Fuels. 2013;27(7):3666-78. https://doi.org/10.1021/ef400330j.

Sheng JJ. Investigation of alkaline-crude oil reaction. Petroleum. 2015;1(1):31-9. https://doi.org/10.1016/j.petlm.2015.04.004.

Sie CY, Nguyen B, Verlaan M, Castellanos-Diaz O, Adiaheno K, Nguyen QP. Viscous oil recovery and in situ deasphalting in fractured reservoirs: part 1. The effect of solvent injection rate. Energy Fuels. 2018;32(1):360-72. https://doi.org/10.1021/acs.energyfuel s.7b03375.

Sie CY, Nguyen B, Verlaan M, Castellanos-Diaz O, Nguyen QP. Viscous oil recovery and in situ deasphalting in fractured reservoirs: part 2: effect of solvent type and temperature. Fuels. 2019;247:294-301. https://doi.org/10.1016/j.fuel.2019.03.044.

Siu AL, Nghiem LX, Gittins SD, Nzekwu BI, Redford DA. Modelling steam-assisted gravity drainage process in the UTF pilot project. In: SPE annual technical conference and exhibition, 6-9 October, Dallas, Texas; 1991. https://doi.org/10.2118/22895-MS.

Svrcek WY, Mehrotra AK. Properties of Peace River bitumen saturated with field gas mixtures. J Can Pet Technol. 1989. https:// doi.org/10.2118/89-02-01.

Walls E, Palmgren C, Kisman K. Residual oil saturation inside the steam chamber during SAGD. J Can Pet Technol. 2003. https:// doi.org/10.2118/03-01-03.

Wang X, Alvarado V. Effect of salinity and $\mathrm{pH}$ on Pickering emulsion stability. In: SPE annual technical conference and exhibition, 21-24 September, Denver, Colorado, USA; 2008. https:// doi.org/10.2118/115941-MS.

Warner HR Jr. The reservoir engineering aspects of waterflooding. SPE monograph series. 2nd ed. Dallas: Society of Petroleum Engineers; 2015. 